\title{
Reversal of Rocuronium-Induced Neuromuscular Block with Neostigmine in the Libyan Patients
}

\author{
Nahd Mohamed Elmaki', Mohamad Anwar Hamza ${ }^{2}$, Abtism Ashour Abdlsalam², Belal S. Shbair ${ }^{2}$, Tomader \\ Mohamed $\mathrm{Ali}^{3}$, Abdurrauf Mohammed Gusbi ${ }^{4}$, Anton Hermann ${ }^{5}$ and Abdul M Gbaj ${ }^{6 *}$ \\ ${ }^{1}$ Department of Pharmacy and Medical Devices, Ministry of Health, Libya \\ ${ }^{2}$ Al-Shyfaa Private Clinic, Libya
}

${ }^{3}$ Departments of Anaesthesia, Tripoli Central Hospital, Libya

${ }^{4}$ Department of Pharmaceutics, University of Tripoli, Libya

${ }^{5}$ Department of Biosciences, University of Salzburg, Austria

${ }^{6}$ Department of Medicinal Chemistry, University of Tripoli, Libya

Received: 眥 September 04, 2018; Published: 制 September 18, 2018

*Corresponding author: Abdul M Gbaj, Department of Medicinal Chemistry, University of Tripoli, Libya

\section{Abstract}

Background: Reversal of the enduring effect of rocuronium by neostigmine is a common procedure performed in the Libyan hospitals. The reversal of the continuing effect of rocuronium by neostigmine was also evaluated.

Methods: eighty adult surgical patients were included in the study using neostigmine $2.5 \mathrm{mg}(0.05-0.07 \mathrm{mg} / \mathrm{kg})$ to reversal the block induced by rocuronium $0.6 \mathrm{mg} / \mathrm{kg}$. Anaesthesia was induced and maintained using i.v. propofol (2.5mg/kg) and fentanyl $(1.5 \mu \mathrm{g} / \mathrm{kg})$. Reversal neuromuscular function was monitored using clinical signs includes patient responsiveness, subjective measurements of muscle strength ( 5 second head lift, hand grasp), eye opening, and tongue extrusion.

Results: Reversal of block was sustained in all patients from the enduring effect of rocuronium by neostigmine. Ninety-six patients were had a similar time of recovery but eleventh were not. There were no serious adverse effects from neostigmine and no significant changes in any measure of safety.

Conclusions: neostigmine is capable of reversing rocuronium-induced blockade in the Libyan patients by monitoring the muscle strength, eye opening, and tongue extrusion.

Keywords: Acetylcholinesterase; Neostigmine; Propofol; Fentanyl; Anaesthesia; Rocuronium

\section{Introduction}

Acetylcholinesterase (AChE) is catalyzing the quick hydrolysis of acetylcholine (ACh) to acetate and choline. The main biological function is being annihilation of impulse transmission at cholinergic synapses. In addition, AChE is believed to have nonclassical roles in nerve and muscle growth and in hematopoiesis $[1,2]$. Additionally, AChE has been concerned in Alzheimer's disease $[3,4]$, hypersensitivity to pesticides and Gulf War syndrome [5]. Rocuronium is frequently used non-depolarizing neuromuscular blocking agents (NMBAs) to facilitate tracheal intubation and affording muscle relaxation throughout surgery. Patients receiving these agents are at danger of outstanding curarization, which is a cause of postoperative pulmonary complications and might augment postoperative mortality [6,7]. Anticholinesterases drugs act mainly by inhibiting acetylcholinesterase and butyryl cholinesterase, prolonging the existence of acetylcholine at the motor end-plate [8]. Additionally, anticholinesterases may have a direct agonistic effect by increasing the release of acetylcholine from presynaptic nerve terminals [9]. For, edrophonium the maximum effective dose is $1.0-1.5 \mathrm{mg} / \mathrm{kg}$ and for neostigmine, is $60-80 \mu \mathrm{g} / \mathrm{kg}$ [8]. The use of two antagonists together is avoided as they are not additive and insufficient reversal can occur. It is not sensible to administer 
extra anticholinesterase if maximal doses of edrophonium $(1.5 \mathrm{mg} /$ $\mathrm{kg})$, neostigmine $(70 \mu \mathrm{g} / \mathrm{kg})$, or pyridostigmine $(350 \mu \mathrm{g} / \mathrm{kg})$ fail to antagonize the residual blockade and might in turn increase the weakness [9]. They are combined with atropine or glycopyrrolate in order to counteract the muscarinic side-effects of these drugs. Neostigmine is the most potent and the preferred drug [9]. Highdose neostigmine or unnecessary use of neostigmine could interpret to increased post-operative respiratory morbidity $[10,11]$. Current rules identify the use of reversal with neostigmine based on the train of four (TOF) monitoring with the neuromuscular monitor. Neostigmine can be given for reversal in patients: who were receiving drugs which enhance the action of NMBAs (inhalational agents). The reversal should not be given in case of TOF counts four in patients receiving anaesthetic drugs which do not boost the blockade by NMBAs (intravenous anaesthetics) $[10,11]$. Moreover, the rules also identify that if the TOF counts less than 2 reversal should not be delayed. A lower dose of neostigmine $(20 \mu \mathrm{g} / \mathrm{kg})$ must be considered if TOF counts four and no fade is apparent or if TOF ratio is 0.4:0.9 on qualitative neuromuscular monitoring [12]. Neostigmine is a cholinesterase inhibitors and it is wildly used in Libya as indicated in the literature as reversal agents for NMBAs $[13,14]$. Sugammadex, which is a novel agent for the reversal of neuromuscular blockade, is adapted gamma-cyclodextrin. Sugammadex is able to form a complex with rocuronium, eradicates it from the circulation and terminates neuromuscular blockade [15]. Sugammadex is a very safe agent with a little risk of serious side effects [16]. The high cost of sugammadex, which is one of the costliest drugs in anesthesia practice, prevents it from being used in Libya as a standard neuromuscular reversal drug. Even though it has been suggested by many doctors in Libya that the cost of sugammadex use in anesthesia could be reduced by shortening the duration of recovery $[17,18]$, further clinical studies on sugammadex in Libya are needed to introduce it to the governmental and private hospitals.

It has been reported that the co-administration of neostigmine with some Nonsteroidal Anti-inflammatory Drugs (NSAIDs, e.g. aspirin) resulted in a synergistic interaction, which may provide evidence of supraspinal antinociception modulation by the increased acetylcholine concentration in the synaptic cleft of cholinergic interneurons. The interaction obtained between neostigmine and the NSAIDs could carry important clinical implications $[19,20]$. Acute toxicity from using cholinesterase inhibitors is related to the inhibition of acetylcholinesterase activity at the neuromuscular junction and in the brain, resulting in depression of circulatory centers in the medulla, weakness of the muscles of respiration, and pulmonary edema [21]. Because of the toxicity relates with inhibition of acetylcholinesterase activity rather than butyryl cholinesterase activity, it would seem reasonable to spotlight on genetic variants of acetylcholinesterase. Though genetic variants of human acetylcholinesterase exist, harmful mutations are uncommon and occur only in the heterozygous state [22]. The aim of this study is to investigate the effects of neostigmine's introduction on the incidence of residual neuromuscular paralysis and postoperative Libyan patient outcome at Al-Shyfaa Private Clinic, Tripoli, Libya.

\section{Materials and Methods}

Qualitative and Quantitative Determination of Neostigmine: The Neostigmine methyl sulphate was obtained from four different companies which are: Neostigmine methyl sulphate (Rotexmedica, Germany); Plantigmine (Polifarma, Turkey); Flagstig (Thexopharma, UK) and Neostigmine (Adeka, Turkey). The reference standard was obtained from Sigma-Aldrich (cat. no. 2126). The identification test for the neostigmin was done using absorbance spectra which were measured on a Jenway UVvisible spectrophotometer, model 6505 (London, UK) using quartz cells of $1.00 \mathrm{~cm}$ path length. The UV-Vis absorbance spectra were recorded in the 200-500 $\mathrm{nm}$ range, and spectral bandwidth of $3.0 \mathrm{~nm}$. It was performed the baseline subtraction of the water for the final spectrum of each solution analyzed. An equivalent to $5 \mathrm{mg}$ of neostigmine methylsulfate Injection according to the labeled amount was taken and completed to $10 \mathrm{~mL}$ with distilled water, and the absorption spectrum of this solution was measured by Ultraviolet-visible Spectrphotometry which should exhibit a principle band at $261 \mathrm{~nm}$. In addition the identity of neostigmine was also determined using HPLC technique by determining the retention time of the major peak in the chromatogram of the four Neostigmine methylsulphate brands preparations compared to the retention time of the major peak in the chromatogram of the standard preparation. The quantitative assay of the neostigmine (Neostigmine Methylsulfate Injection) was perofromed by Waters HPLC using the Japanese Pharmacopoeia (Sixteenth Edition), page 1168.

Molecular Docking: The starting geometry of neostigmine was constructed using chem3D Ultra (version 8.0, Cambridgesoft Com., USA). The optimized geometry of neostigmine with the lowest energy was used in the molecular docking. The crystal structures of human acetylcholinesterase in a complex with a transition-state analogue were downloaded from the Protein Data Bank. The molecular dockings of neostigmine with human acetylcholinesterase was accomplished by AutoDock 4.2software from the Scripps Research Institute (TSRI). Firstly, the polar hydrogen atoms were added into human acetylcholinesterase and neostigmine molecules. Then, the partial atomic charges of the human acetylcholinesterase and neostigmine molecule were calculated using Kollman methods [23]. In the process of molecular docking, the grid maps of dimensions ( $62 \AA$ X $62 \AA$ X $62 \AA$ ) with a grid-point spacing of $0.376 \AA$ and the grid boxes is centered. The number of genetic algorithm runs, and the number of evaluations was set to 100 . All other parameters were default settings. Cluster 
analysis was performed on the results of docking by using a root mean square (RMS) tolerance of $2.0 \AA$, and this was dependent on the binding free energy. Lastly, the dominating configuration of the binding complex of neostigmine and human acetylcholinesterase with minimum energy of binding can be determined.

Study Design and Patient Selection: This study was conducted at APC (Al-Shyfaa Private Clinic, Tripoli, Libya) during July/August 2018. The protocol was accepted by the Independent Ethics Committee at the clinic and conducted in fulfillment with the recent amendment of the Declaration of Libyan Guidelines, present regulatory requirements and Good Clinical Practice. Eighty patients were included in the study and they were aged 20-60 years and experiencing surgery in the supine position under general anaesthesia (Laparoscopy surgery) which are requiring muscle relaxation. Patients were excluded if they were anticipated to have a neuromuscular disorder, difficult intubation for anatomical reasons; family history of malignant hyperthermia, significant renal dysfunction; or a known allergy to NMBAs, narcotics, or other medication used throughout general anaesthesia. Patients receiving anticonvulsants, antibiotics, or magnesium at a time possible to hinder with neuromuscular block effect were also excluded. Female patients who were breastfeeding, pregnant, childbearing potential were also excluded. All patients have presented written consent. Subject numbers were allocated to patients in chronological order of their participation into this study. Anaesthesia was induced with i.v. propofol $(2.5 \mathrm{mg} / \mathrm{kg})$ and fentanyl $(1.5 \mu \mathrm{g} / \mathrm{kg})$ and maintained using a continuous infusion of propofol and additional increments or infusions of analgesic as needed. After the establishment of neuromuscular scrutinizing, rocuronium $0.6 \mathrm{mg} / \mathrm{kg}$ was given as an i.v. bolus over 10 seconds into a quick running i.v. infusion. Tracheal intubation was performed once the maximum neuromuscular block effect is achieved and intermittent positive pressure ventilation started to achieve a standard end-tidal $\mathrm{CO}_{2}$ concentration (4.5-5.5 $\mathrm{kPa}$ ). Additional doses of rocuronium $0.1-0.2 \mathrm{mg} / \mathrm{kg}$ up to a highest of two dosages were administered if required. Once the last dose of NMBA was administered and reappearance of $\mathrm{T} 2$ then neostigmine $0.05-0.07 \mathrm{mg} / \mathrm{kg}$ (maximum of $2.5 \mathrm{mg}$ ) was administered within 10 seconds into a quick-running i.v. infusion.

Monitoring: Using clinical signs comprises patient responsiveness, individual measurements of eye opening, muscle strength (5 second head lift, hand grasp), and tongue extrusion. After extubation (removal of the endotracheal tube (ETT) and it is the final step in liberating a patient from mechanical ventilation), clinical evaluation of level of consciousness and neuromuscular recovery ( $5 \mathrm{~s}$ head lift and general muscle weakness on a scale of 1-9) were carried out each 15 min until the first continued head lift for 5 second was attained. Oxygen saturation using breathing frequency and pulse oximetry were watched during anesthesia and in the recovery room for at least one hour after operation. Heart rate and arterial blood pressure were traced at the screening, before administration of rocuronium, before and two, five, ten, and thirty minutes after administration of neostigmine, and during the post-anaesthetic visit, which was carried out within the first twenty-four postoperative hours. Diastolic pressure of $\leq 45$ or $\geq 95$ $\mathrm{mm} \mathrm{Hg}$, systolic arterial pressure of $\leq 90$ or $\geq 160 \mathrm{~mm} \mathrm{Hg}$, and heart rates of $\leq 50$ or $\geq 120$ beats per minutes were admitted as clinically noteworthy. The ECG was monitored constantly in the operating theater and the recovery ward in a way consistent with classical anaesthetic practice APC (Al-Shyfaa Private Clinic, Tripoli, Libya). Physical examination was done prior to the surgery and at the postanaesthetic visit. Ten milliliters of blood samples were withdrawn from every patient for haematology and biochemistry evaluations prior administration of rocuronium, from four to six hours after administration of neostigmine, and at the post-anaesthetic visit. Urine samples were gathered for analysis on the day prior surgery or on the same day of surgery before anaesthesia and at the postanaesthetic visit.

Anesthesia and Neuromuscular Block: To evaluate the efficacy of neostigmine, the time from the start of administration of neostigmine to recovery was determined. In addition, the clinical signs of recovery after extubation, but before transfer to the recovery room and before discharge from the recovery room were also recorded. The time from administration of the intubating dose of rocuronium to event of highest block was also studied (i.e. onset time).

Statistics: Results were expressed as mean \pm standard error (SE). Statistical differences between the three parameters (muscle strength, eye opening, and tongue extrusion) were evaluated by one-way analysis of variance (ANOVA). All data were analyzed with SPSS 10.0 software. $\mathrm{P}<0.05$ was considered statistically significant.

\section{Results and Discussion}

Qualitative and Quantitative Determination of Neostigmine: The qualitative determination of neostigmine was confirmed by the presence of the principle band at $261 \mathrm{~nm}$ of the UVvisible absorption spectrum of the four Neostigmine methlsulphate brands which is corresponding to the spectrum of the neostigmine reference standard (cat. no. 2126, Sigma-Aldrich) and all spectra exhibit identical absorption spectrum. In addition, retention time ( $9 \mathrm{~min}$ ) of HPLC chromatogram is also confirming the identity of the neostigmine. Regarding to the quantitative assay; the HPLC results have shown that the content profiles of the four brands are within the pharmacopeia limit which is not less than $93 \%$ and not more than $107 \%$ of the labeled amount of Neostigmine methylsulphate C13H22N2O6S:334.39.

Molecular Docking Analysis: The modeling study was performed in this paper showed great interactions between neostigmine and human acetylcholinesterase. The binding energies 
of neostigmine and acetylcholine human acetylcholinesterase were -6.52 and $-4.83 \mathrm{kcal} / \mathrm{mole}$, respectively. The geometry of docking obtained with neostigmine with human acetylcholinesterase as shown in Figure 1. Neostigmine was able to form hydrogen bonds (HBs) with the residues Try337 of the enzyme, pi-pi stacking with the residue Trp86 and Pi-alkyl interaction with the residue Trp86. In addition, the molecular docking results showed that other amino acids residues are involved in the interactions with the neostigmine.

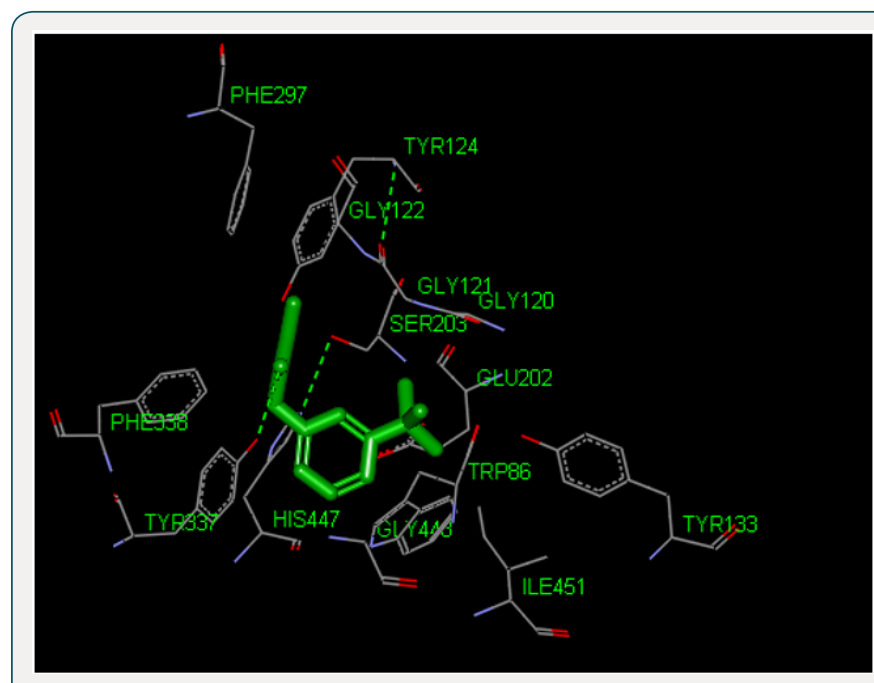

Figure 1: Three-dimensional representation of neostigmine interacting with active site of target macromolecule human acetylcholinesterase.

Clinical Elements: Eighty patients were randomized to treatment (rocuronium-neostigmine, $\mathrm{n}=80$ ). All treated patients had three efficacy parameters that assessment carried out as shown in Table 1. The time from the start of administration of the reversal agent (neostigmine) to recovery, 11 patients used neostigmine had very late recovery time ( $\geq 9 \mathrm{~min}$ ). These data were not excluded from the analysis. Mean systolic and diastolic arterial pressures and heart rates were not very similar in all patients. Systolic arterial pressures of $\geq 150$ or $\leq 90 \mathrm{~mm} \mathrm{Hg}$, diastolic pressures of $\geq 98$ or $\leq 45 \mathrm{~mm} \mathrm{Hg}$, and heart rates of $\geq 121$ or $\leq 55$ beats $\mathrm{min}^{-1}$ were observed in six patients used neostigmine. None of these was believed clinically important. Full recovery from neuromuscular block postoperative is crucial since residual neuromuscular block may augment morbidity (hypoxia, dyspnea, airway obstruction,). The use and monitoring of classical reversal agent is important to avoid residual neuromuscular blockage [24,25]. The usual neostigmine therapeutic dose is $0.04-0.07 \mathrm{mg} / \mathrm{kg}$ whereas a toxic dose is $0.08 \mathrm{mg} / \mathrm{kg}$. Neostigmine uses has restrictions such as recurarization, muscarinic effect, weakness of respiratory muscle and ceiling effect [26,27]. Some adverse effects of neostigmine are dependent on the dose. Recent studies were performed to estimate the lowest neostigmine dose to obtain recovery from neuromuscular block (TOF ratio, TOFR 90\%, the lower TOFR value, the deeper the neuromuscular blockade) lacking adverse effects
[28]. The allocation of essential characteristic in this study is including age, gender, body weight and occupation for all patients. The duration of surgery in this study was limited to 30-90 minutes owing to the pharmacokinetics of rocuronium. Rocuronium has a moderate duration of action between 35-75 minutes [29,30]. However, Debane et al. has reported that the pharmacological effect of rocuronium is existing until 120 minutes after single dose administration [31]. All patients do not need to use additional neuromuscular blocking agents dose during operation in this study. Table 1 showed that a dose of neostigmine $2.5 \mathrm{mg}$ was as efficient as attuned dose based on the TOFR value for reversal of single dose rocuronium $0.6 \mathrm{mg} / \mathrm{kg}$. Table 1 showed that the total patients who reached TOFR $\geq 90 \%$ at $0-9$ minutes after reversal administration were 69 and who reached TOFR $\geq 90 \%$ at 10-20 minutes after reversal administration were 11 (underline numbers). However, the differences were not statistically significant $(\mathrm{p}=0.718, \mathrm{~F}=0.331$, F critical 3.034). All patients (except one patients had 19 minutes) had already reached TOFR $\geq 90 \%$ in interval of 0-15 minutes after reversal administration, the data obtained in this study in which the mean of the time required to reach TOFR $\geq 90 \%$ after reversal was 0-15 minutes were consistent with the data reported by FuchsBuder et. al which showed that the time required was 10 or more minutes [32]. In addition to that our results are consistent with other study by Cappellini et. al who reported that the recovery time of the patient was 10 minutes after neostigmine $0.01-0.03 \mathrm{mg} / \mathrm{kg}$ with a shallow degree of neuromuscular block at the end surgery [33].

Table 1 also showed that the recovery time of the patient number 25 (who is on Aspirin tablets) was 17-20 minutes after neostigmine administration and this delayed action could be related to the fact that co-administration of neostigmine with some aspirin or other NSAIDs like diclofenac resulted in a synergistic interaction, which may provide evidence of supraspinal antinociception modulation by the increased acetylcholine availability in the synaptic cleft of cholinergic interneurons. The interaction obtained in this study between neostigmine and the NSAIDs have important clinical implications and it is consistent with the literature as reported by Hugo et.al [20]. For the present study, patients No. 12, 41, 45, 53, $59,61,64,72,74$, and 77 had delayed action could be related to the mutational structure perturbation approach to expose longrange communication and the presence of conformational switches in the interior of the acetylcholinesterase enzyme. It is known that mutations are changes to the base sequence. The base sequence determines the amino acid sequence. A different base sequence therefore codes for a different amino acid sequence. Amino acids interact with each other by H-bonds, ionic bonds, and disulphide bridges. When the amino acids sequence of the acetylcholinesterase is changing then these interactions and bonds will be affected and the 3D shape of the acetylcholinesterase changes (tertiary structure). acetylcholinesterase work by interacting with substrates 
through their 'active site' as shown in Figure 1. A change in acetylcholinesterase shape will change the shape of the active site. The neostigmine cannot bind to the new shape of the active site so no acetylcholinesterase-neostigmine complexes are formed easily so the acetylcholinesterase cannot be inhibited or inhibited very slowly. Hasin et. al. has reported a total of 13 acetylcholinesterase single nucleotide polymorphisms (SNPs) and they might have deleterious adverse drug responses to acetylcholinesterase inhibitors [34]. In addition, Johnson and Moore have reported that the homo sapiens acetylcholinesterase mutations and they study the active site residues and they found the mutations could lead to differences in both steric and electrostatic properties of the active site [35]. The delayed onset of action of neostigmine as shown in Table 1 could be attributed to SNPs and mutation in Libyan patients. Our findings in addition to the published record suggest that the genetic variation could effect on neostigmine pharmacological action. Further studies need on Libyan people to be done in the future in order to confirm these results.

Table 1: Time (min) from start of administration of neostigmine to recovery.

\begin{tabular}{|c|c|c|c|c|c|c|c|c|c|c|c|c|c|c|c|}
\hline $\begin{array}{l}\text { pt. } \\
\text { no }\end{array}$ & Age & gender & weight & occupation & M.S.A ${ }^{1}$ & E. $0^{2}$ & T.E ${ }^{3}$ & pt. no & age & gender & weight & occupation & M.S.A & E.0 & T.E \\
\hline 1 & $30-40$ & M & $60-70$ & EMP. & 3 & 3 & 10 & 41 & $20-30$ & M & $60-70$ & EMP & 11 & 11 & 11 \\
\hline 2 & $20-30$ & M & $60-70$ & EMP. & 5 & 5 & 10 & 42 & $30-40$ & $\mathrm{~F}$ & $70-80$ & UN.EMP & 5 & 5 & 5 \\
\hline 3 & $30-40$ & $\mathrm{~F}$ & $60-70$ & UN EMP. & 5 & 0 & 0 & 43 & $40-50$ & $\mathrm{~F}$ & $70-80$ & EMP & 6 & 6 & 6 \\
\hline 4 & $50-60$ & F & $60-70$ & EMP. & 5 & 5 & 8 & 44 & $50-60$ & $\mathrm{~F}$ & over 90 & UN.EMP & 5 & 5 & 5 \\
\hline 5 & $40-50$ & M & $60-70$ & EMP. & 3 & 3 & 3 & 45 & $50-60$ & $\mathrm{~F}$ & $80-90$ & EMP & 12 & 12 & 12 \\
\hline 6 & $20-30$ & M & over 90 & STUDENT & 9 & 8 & 9 & 46 & $50-60$ & $\mathrm{~F}$ & $70-80$ & UN.EMP & 6 & 7 & 7 \\
\hline 7 & $20-30$ & F & $50-60$ & STUDENT & 5 & 6 & 6 & 47 & $40-50$ & $\mathrm{~F}$ & $80-90$ & UN.EMP & 2 & 2 & 3 \\
\hline 8 & $40-50$ & M & $60-70$ & EMP. & 3 & 3 & 3 & 48 & $20-30$ & M & $70-80$ & EMP & 9 & 9 & 9 \\
\hline 9 & $20-30$ & $\mathrm{M}$ & $70-80$ & EMP. & 8 & 8 & 8 & 49 & $20-30$ & $\mathrm{~F}$ & $60-70$ & EMP & 5 & 5 & 5 \\
\hline 10 & $40-50$ & $\mathrm{~F}$ & $80-90$ & EMP. & 3 & 3 & 3 & 50 & $30-40$ & $\mathrm{M}$ & $60-70$ & EMP & 3 & 3 & 3 \\
\hline 11 & $40-50$ & $\mathrm{~F}$ & $60-70$ & UN EMP. & 4 & 4 & 4 & 51 & $20-30$ & $\mathrm{M}$ & $60-70$ & EMP & 6 & 6 & 6 \\
\hline 12 & $30-40$ & $\mathrm{~F}$ & $70-80$ & EMP. & 14 & 14 & 14 & 52 & $40-50$ & $\mathrm{~F}$ & 135 & UN.EMP & 5 & 6 & 6 \\
\hline 13 & $40-50$ & $\mathrm{~F}$ & $80-90$ & EMP. & 7 & 7 & 7 & 53 & $30-40$ & F & $60-70$ & UN.EMP & 10 & 10 & 10 \\
\hline 14 & $30-40$ & M & $60-70$ & EMP. & 5 & 6 & 6 & 54 & $30-40$ & $\mathrm{~F}$ & $70-80$ & UN.EMP & 6 & 6 & 6 \\
\hline 15 & $40-50$ & $\mathrm{~F}$ & $60-70$ & UN EMP. & 3 & 3 & 3 & 55 & $40-50$ & $\mathrm{~F}$ & $70-80$ & UN.EMP & 9 & 9 & 9 \\
\hline 16 & $30-40$ & $\mathrm{~F}$ & $70-80$ & UN EMP. & 2 & 2 & 2 & 56 & $20-30$ & M & $60-70$ & EMP & 6 & 6 & 6 \\
\hline 17 & $30-40$ & F & $70-80$ & EMP. & 3 & 3 & 3 & 57 & $30-40$ & M & $70-80$ & EMP & 5 & 6 & 6 \\
\hline 18 & $50-60$ & $\mathrm{~F}$ & $80-90$ & UN EMP. & 3 & 3 & 3 & 58 & $30-40$ & $\mathrm{~F}$ & $70-80$ & EMP & 6 & 6 & 6 \\
\hline 19 & $40-50$ & $\mathrm{~F}$ & $60-70$ & UN EMP. & 5 & 6 & 6 & 59 & $20-30$ & F & $60-70$ & UN.EMP & 10 & 11 & 11 \\
\hline 20 & $30-40$ & $\mathrm{~F}$ & $70-80$ & UN EMP. & 5 & 5 & 5 & 60 & $50-60$ & $\mathrm{M}$ & $70-80$ & EMP & 7 & 7 & 7 \\
\hline 21 & $20-30$ & F & $70-80$ & EMP. & 7 & 5 & 5 & 61 & $40-50$ & $\mathrm{~F}$ & $70-80$ & UN.EMP & 13 & 13 & 13 \\
\hline 22 & $40-50$ & $\mathrm{~F}$ & $50-60$ & EMP. & 4 & 3 & 4 & 62 & $30-40$ & M & $70-80$ & EMP & 8 & 8 & 8 \\
\hline 23 & $20-30$ & $\mathrm{~F}$ & $60-70$ & UN.EMP & 2 & 2 & 2 & 63 & $30-40$ & M & $70-80$ & EMP & 4 & 4 & 4 \\
\hline 24 & $40-50$ & F & $60-70$ & UN.EMP & 4 & 3 & 3 & 64 & $50-60$ & $\mathrm{~F}$ & $60-70$ & UN.EMP & 13 & 13 & 13 \\
\hline 25 & $50-60$ & F & $80-90$ & UN.EMP & 19 & 17 & 19 & 65 & $30-40$ & $\mathrm{~F}$ & $60-70$ & EMP & 6 & 6 & 6 \\
\hline 26 & $30-40$ & $\mathrm{~F}$ & over 90 & UN.EMP & 5 & 5 & 6 & 66 & $50-60$ & $\mathrm{~F}$ & $70-80$ & UN.EMP & 4 & 4 & 4 \\
\hline 27 & $30-40$ & $\mathrm{~F}$ & $70-80$ & UN.EMP & 3 & 2 & 2 & 67 & $30-40$ & $\mathrm{~F}$ & $70-80$ & EMP & 5 & 6 & 6 \\
\hline 28 & $40-50$ & $\mathrm{~F}$ & $50-60$ & UN.EMP & 3 & 4 & 4 & 68 & $50-60$ & $\mathrm{~F}$ & $70-80$ & UN.EMP & 6 & 6 & 6 \\
\hline 29 & $30-40$ & $\mathrm{~F}$ & $60-70$ & UN.EMP & 8 & 8 & 8 & 69 & $40-50$ & $\mathrm{~F}$ & $70-80$ & EMP & 5 & 5 & 5 \\
\hline 30 & $30-40$ & $\mathrm{~F}$ & $70-80$ & UN.EMP & 3 & 3 & 3 & 70 & $50-60$ & $\mathrm{M}$ & $70-80$ & EMP & 6 & 6 & 6 \\
\hline 31 & $20-30$ & $\mathrm{M}$ & $60-70$ & EMP. & 9 & 6 & 8 & 71 & $50-60$ & M & $70-80$ & UN.EMP & 6 & 6 & 6 \\
\hline 32 & Less & $\mathrm{F}$ & $50-60$ & CHILD & 3 & 3 & 5 & 72 & $50-60$ & $\mathrm{~F}$ & $70-80$ & UN.EMP & 11 & 11 & 11 \\
\hline 33 & $50-60$ & $\mathrm{~F}$ & $60-70$ & EMP. & 4 & 4 & 6 & 73 & $30-40$ & $\mathrm{M}$ & $60-70$ & EMP & 5 & 5 & 5 \\
\hline 34 & $30-40$ & $\mathrm{~F}$ & $50-60$ & EMP. & 3 & 3 & 5 & 74 & $30-40$ & $\mathrm{M}$ & 103 & EMP & 10 & 10 & 10 \\
\hline 35 & $20-30$ & M & $60-70$ & EMP. & 5 & 4 & 7 & 75 & $30-40$ & $\mathrm{~F}$ & $70-80$ & UN.EMP & 7 & 7 & 7 \\
\hline 36 & $20-30$ & $\mathrm{~F}$ & $50-60$ & EMP. & 6 & 7 & 6 & 76 & $30-40$ & $\mathrm{~F}$ & $60-70$ & EMP & 6 & 6 & 6 \\
\hline
\end{tabular}




\begin{tabular}{|c|c|c|c|c|c|c|c|c|c|c|c|c|c|c|c|}
\hline 37 & $40-50$ & F & $70-80$ & EMP. & 1 & 2 & 2 & 77 & $50-60$ & F & $70-80$ & UN.EMP & 12 & 12 & 12 \\
\hline 38 & $50-60$ & M & $70-80$ & UN.EMP & 2 & 2 & 2 & 78 & $50-60$ & $\mathrm{~F}$ & $80-90$ & UN.EMP & 3 & 3 & 3 \\
\hline 39 & $30-40$ & $\mathrm{~F}$ & over 90 & EMP. & 5 & 5 & 5 & 79 & $30-40$ & $F$ & $80-90$ & UN.EMP & 4 & 6 & 6 \\
\hline 40 & $50-60$ & $M$ & $70-80$ & UN.EMP & 8 & 8 & 8 & 80 & $30-40$ & $\mathrm{~F}$ & over 90 & EMP & 6 & 6 & 6 \\
\hline
\end{tabular}

${ }^{1}$ M.S.A = Muscle Strength Assessment (5-second head lift, hand grasp),

${ }^{2} \mathrm{E} . \mathrm{O}=$ eye opening

${ }^{3} \mathrm{~T} . \mathrm{E}=$ tongue extrusion

\section{Conclusion}

This Libyan study was the first comparative study between the three parameters (measurements of muscle strength, eye opening, and tongue extrusion) that are used to reversal of the enduring effect of rocuronium by neostigmine. It is found that rocuroniuminduced neuromuscular block and can be reversed by neostigmine. It increased the amount of safety data available about neostigmine, although this was not the main reason for the study. Clinical signs of recovery were similar with the three parameters, which is to be expected. This indicates that the results presented are realistic in the Libyan patients. The faster time to recovery with most of patients $(n=69)$ compared with eleventh patients $(n=11)$ in this study is consistent with that previously reported. The rapid time to recovery with neostigmine observed in Libyan patients is similar to that reported in previous studies, demonstrating a consistency in observed efficacy.

\section{References}

1. Sternfeld M, Ming G, Song H, Sela K, Timberg R, et al. (1998) Acetylcholinesterase enhances neurite growth and synapse development through alternative contributions of its hydrolytic capacity, core protein, and variable C termini. J Neurosci 18(4): 1240-1249.

2. Kawashima K, Fujii $\mathrm{T}$ (2000) Extraneuronal cholinergic system in lymphocytes. Pharmacol Ther 86(1): 29-48.

3. Barai P, Raval N, Acharya S, Borisa A, Bhatt H, et al. (2018) Neuroprotective effects of bergenin in Alzheimer's disease: Investigation through molecular docking, in vitro and in vivo studies. Behav Brain Res 356: 1840.

4. Hussein W, Saglik BN, Levent S, Korkut B, Ilgin S, et al. (2018) Synthesis and biological evaluation of new cholinesterase inhibitors for Alzheimer's disease. Molecules 23(8).

5. Soreq H, Seidman S (2001) Acetylcholinesterase--new roles for an old actor. Nat Rev Neurosci 2(4): 294-302.

6. Heggeri VM, Harbishettar AS, Deka A, Rajkhowa T (2015) Intubating conditions of two different doses of rocuronium at 60 seconds; by clinical assessment; and with T.O.F response of adductor pollicis muscle. J Clin Diagn Res 9(9): UC24-UC28.

7. Geldner G, Buder FT, Hofmockel R, Diefenbach C, Ulm K, et al. (2003) The use of muscle relaxants for routine induction of anesthesia in Germany. Anaesthesist 52(5): 435-441.

8. Weichert I, Ortuno RR, Tolonen J, Soe T, Lebus C, et al. (2018) Anticholinergic medications in patients admitted with cognitive impairment or falls (AMiCI). The impact of hospital admission on anticholinergic cognitive medication burden. Results of a multicentre observational study. J Clin Pharm Ther 43(5): 682-694.

9. Lorke DE, Petroianu GA (2018) Reversible cholinesterase inhibitors as pretreatment for exposure to organophosphates. A review. J Appl Toxicol.
10. Sasaki N, Meyer MJ, Malviya SA, Stanislaus AB, MacDonald T, et al. (2014) Effects of neostigmine reversal of nondepolarizing neuromuscular blocking agents on postoperative respiratory outcomes: A prospective study. Anesthesiology 121(5): 959-968.

11. Sundrup GM, Henneman JP, Sandberg WS, Bateman BT, Uribe JV, et al. (2012) Intermediate acting non-depolarizing neuromuscular blocking agents and risk of postoperative respiratory complications: Prospective propensity score matched cohort study. BMJ 345: e6329.

12. Brull SJ, Murphy GS (2010) Residual neuromuscular block: Lessons unlearned. Part II: Methods to reduce the risk of residual weakness. Anesth Analg 111(1): 129-140.

13. Cappellini I, Picciafuochi F, Ostento D, Danti G, De Gaudio AR, et al. (2018) Recovery of muscle function after deep neuromuscular block by means of diaphragm ultrasonography and adductor of pollicis acceleromyography with comparison of neostigmine vs. sugammadex as reversal drugs: Study protocol for a randomized controlled trial. Trials 19(1): 135.

14. Abrishami A, Ho J, Wong J, Yin L, Chung F (2009) Sugammadex a selective reversal medication for preventing postoperative residual neuromuscular blockade. Cochrane Database Syst Rev (4): CD007362.

15. Naguib M (2007) Sugammadex: Another milestone in clinical neuromuscular pharmacology. Anesth Analg 104(3): 575-581.

16. Otomo S, Iwasaki H, Takahoko K, Onodera Y, Sasakawa T, et al. (2014) Prediction of optimal reversal dose of sugammadex after rocuronium administration in adult surgical patients. Anesthesiol Res Pract, pp. 848051.

17. Ledowski T, Hillyard S, Kozman A, Johnston F, Gillies E, et al. (2012) Unrestricted access to sugammadex: Impact on neuromuscular blocking agent choice, reversal practice and associated healthcare costs. Anaesth Intensive Care 40(2): 340-343.

18. Tallarida RJ (2002) Commentary on neostigmine interactions with non steroidal anti-inflammatory drugs by Miranda et al. Br J Pharmacol 135(7): 1589-1590.

19. Miranda HF, Sierralta F, Pinardi G (2002) Neostigmine interactions with non steroidal anti-inflammatory drugs. Br J Pharmacol 135(7): 15911597.

20. Kang L, Gao XH, Liu HR, Men X, Wu HN, et al. (2018) Structureactivity relationship investigation of coumarin-chalcone hybrids with diverse side-chains as acetylcholinesterase and butyrylcholinesterase inhibitors. Mol Divers.

21. Valle AM, Radic Z, Rana BK, Mahboubi V, Wessel J, et al. (2011) Naturally occurring variations in the human cholinesterase genes: Heritability and association with cardiovascular and metabolic traits. J Pharmacol Exp Ther 338(1): 125-133.

22. Tiwari R, Mahasenan K, Pavlovicz R, Li C, Tjarks W (2009) Carborane clusters in computational drug design: A comparative docking evaluation using Auto Dock, FlexX, Glide, and Surflex. J Chem Inf Model 49(6): 15811589.

23. Murphy GS, Brull SJ (2010) Residual neuromuscular block: Lessons unlearned. Part I: definitions, incidence, and adverse physiologic effects of residual neuromuscular block. Anesth Analg 111(1): 120-128. 
24. Song IA, Seo KS, Oh AY, No HJ, Hwang JW, et al. (2015) Timing of reversal with respect to three nerve stimulator end-points from cisatracuriuminduced neuromuscular block. Anaesthesia 70(7): 797-802.

25. Thilen SR, Ng IC, Cain KC, Treggiari MM, Bhananker SM (2018) Management of rocuronium neuromuscular block using a protocol for qualitative monitoring and reversal with neostigmine. $\mathrm{Br} \mathrm{J}$ Anaesth 121(2): 367-377.

26. Dutu M, Ivascu R, Tudorache O, Morlova D, Stanca A, et al. (2018) Neuromuscular monitoring: an update. Rom J Anaesth Intensive Care 25(1): 55-60.

27. Eikermann M, Fassbender P, Malhotra A, Takahashi M, Kubo S, et al. (2007) Unwarranted administration of acetylcholinesterase inhibitors can impair genioglossus and diaphragm muscle function. Anesthesiology 107(4): 621-629.

28. Tran DT, Newton EK, Mount VA, Lee JS, Wells GA, et al. (2015) Rocuronium versus succinylcholine for rapid sequence induction intubation. Cochrane Database Syst Rev (10): CD002788.
29. Diefenbach C, Nigrovic V, Mellinghoff H, Buzello W (1997) [Muscle relaxants. New substances and neuromuscular monitoring]. Anaesthesist 46(1): 3-13.

30. Debaene B, Plaud B, Dilly MP, Donati F (2003) Residual paralysis in the PACU after a single intubating dose of nondepolarizing muscle relaxant with an intermediate duration of action. Anesthesiology 98(5): 10421048.

31. Buder FT, Meistelman C, Alla F, Grandjean A, Wuthrich Y, et al. (2010) Antagonism of low degrees of atracurium-induced neuromuscular blockade: Dose-effect relationship for neostigmine. Anesthesiology 112(1): 34-40.

32. Hasin Y, Avidan N, Bercovich D, Korczyn A, Silman I, et al. (2004) A paradigm for single nucleotide polymorphism analysis: the case of the acetylcholinesterase gene. Hum Mutat 24(5): 408-416.

33. Johnson G, Moore SW (2007) Acetylcholinesterase readthrough peptide shares sequence similarity to the 28-53 peptide sequence of the acetylcholinesterase adhesion-mediating site and competes for ligand binding in vitro. J Mol Neurosci 31(2): 113-126.

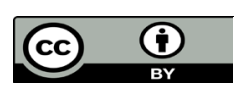

This work is licensed under Creative Commons Attribution 4.0 License

To Submit Your Article Click Here:

Submit Article

DOI: $10.32474 /$ LOJPCR.2018.01.000103

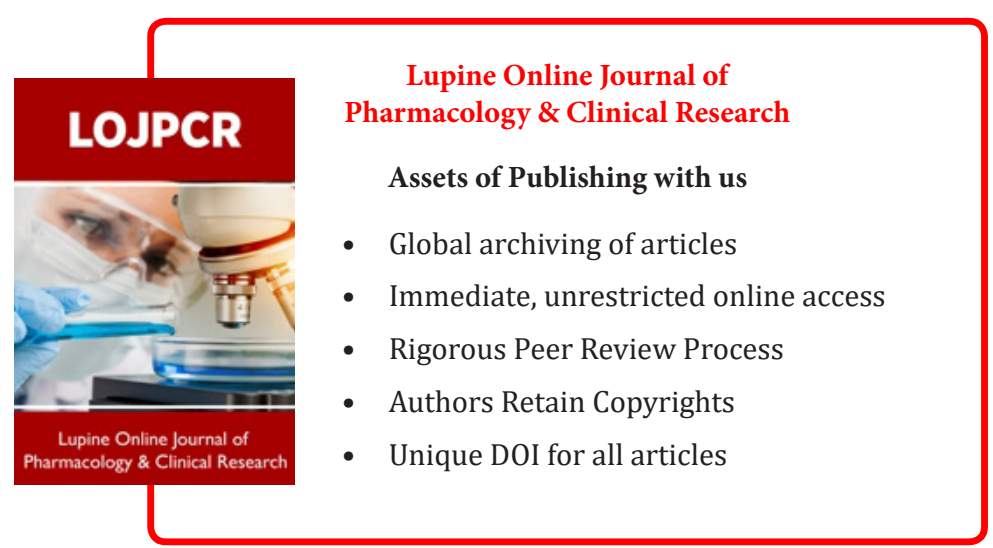

